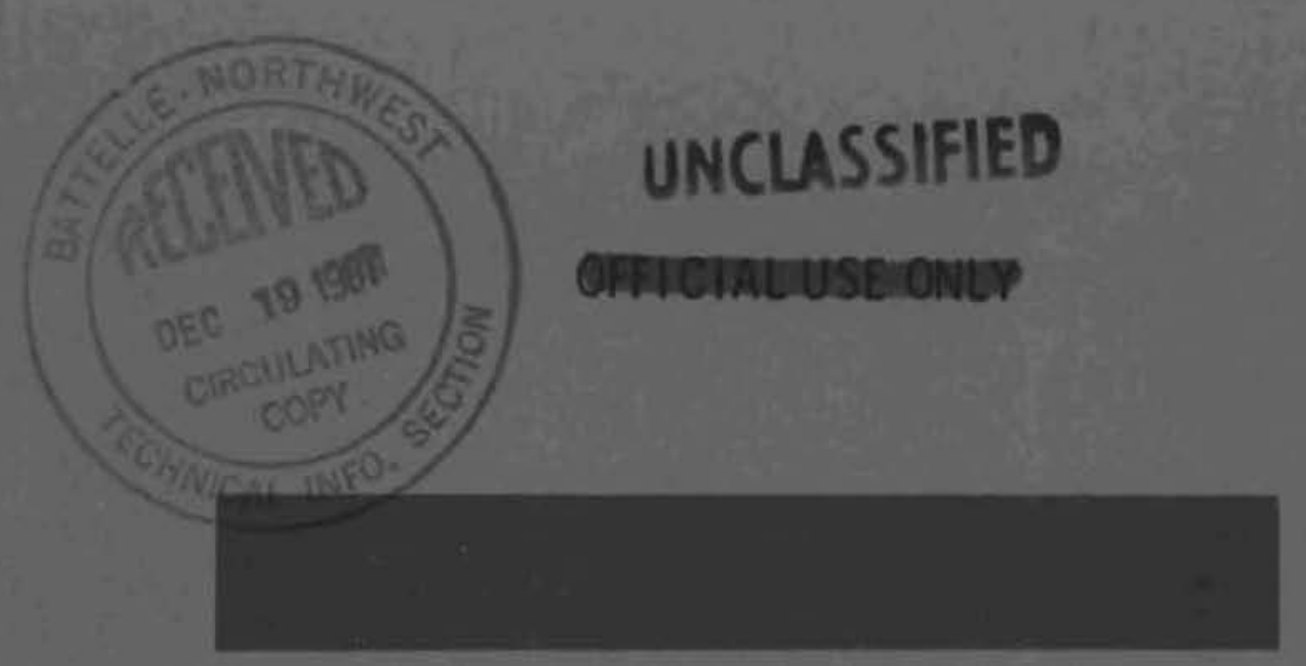

\title{
BNWL- 648
}

FAST FLUX

TEST FACILITY

PROJECT REPORT

\section{DECAY HEAT DEPOSITION}

FROM IRRADIATED FTR FUEL BUNDLE

\author{
W. L. Bunch
}

December 1967

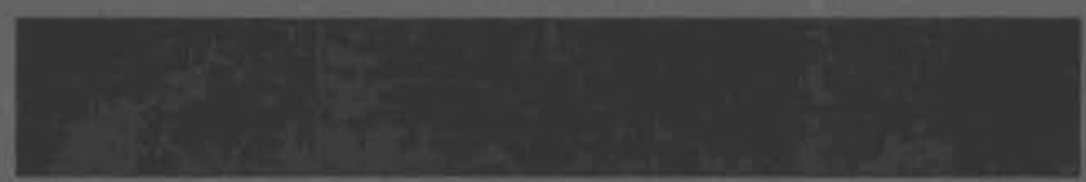

AEC RESEARCH \& DEVELOPMENT REPORT

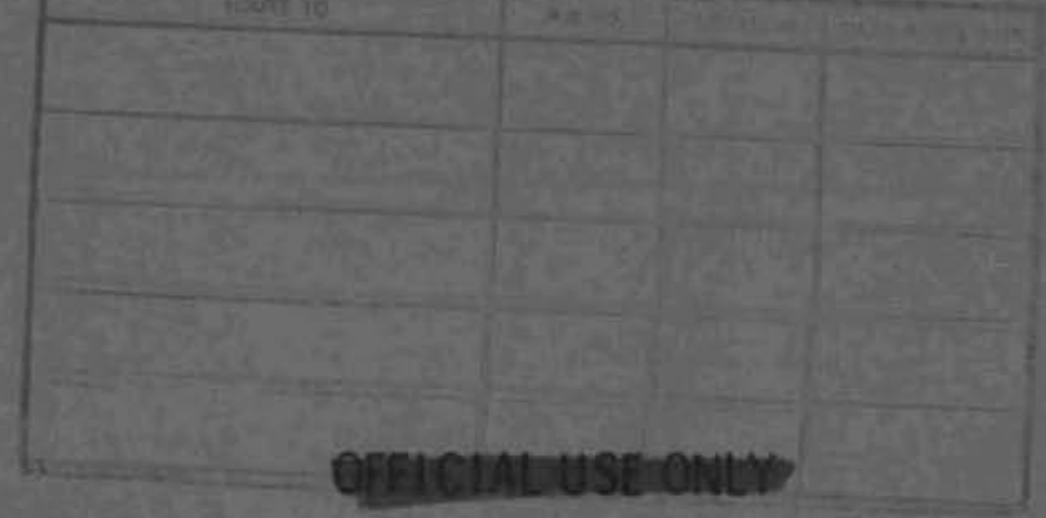

\section{UNCLASSIFIED} BAT T E LLE B NORTHWEST

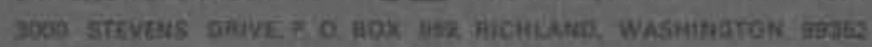




\section{Promesrutes}

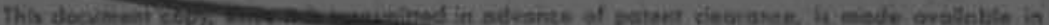

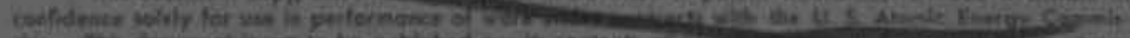

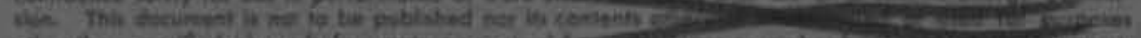

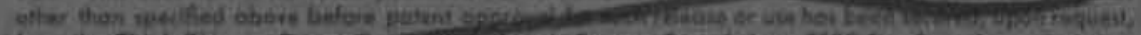

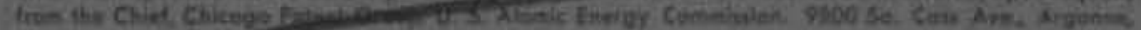
Alliobia

\section{PRETIINAFY REPOHS}

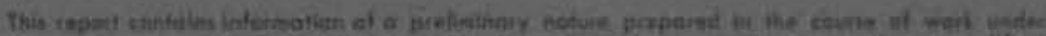

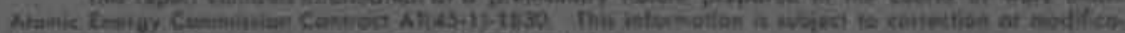
fien unon this cellactian end evituugion of odditional thes.

\section{Iibest. Norial}

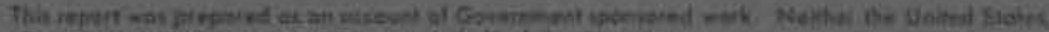
ker the Commition hat anv ietron anieg on bahalf of the Comminish.

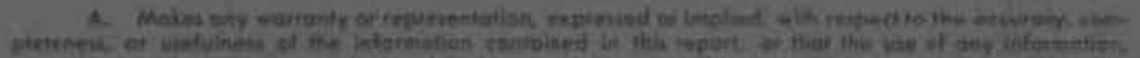

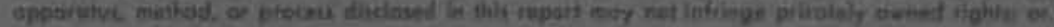

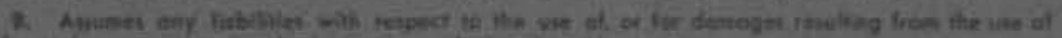

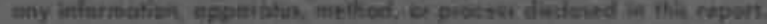

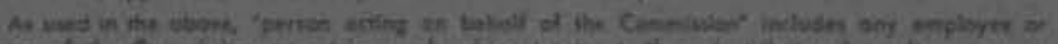

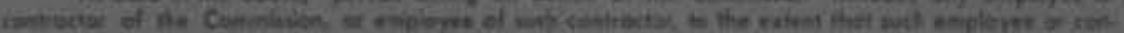

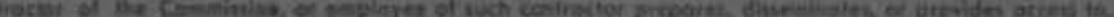

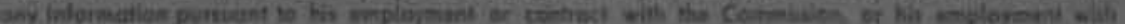
with remoesip?

\section{PACIFIC NORTHWEST LABORATORY}

EICHLAN, WASMNGTON

operated by

BATTELLE MEMORIAL INSTITUTE

for the

UNITED STATES ATOMIC ENERGY COMMISSION UNDER CONTRACT AT(45-1)-1830 

inensinsititen
BNWL- 648

DECAY HEAT DEPOSITION FROM IRRADIAIED FTR FUEL BUNDLE

by

W. I. Bunch

Shielding Analysis Unit

FFIT Reactor Physics Section

December 5, 1967

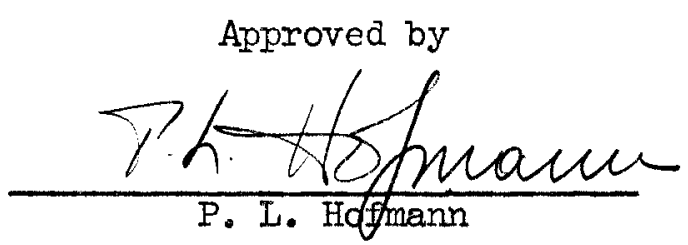

PACIFIC NORTHWEST LABORATORY

RICHLAND, WASHINGTON

in! $\times 1: 50$ 
TABLE OF CONTENTS

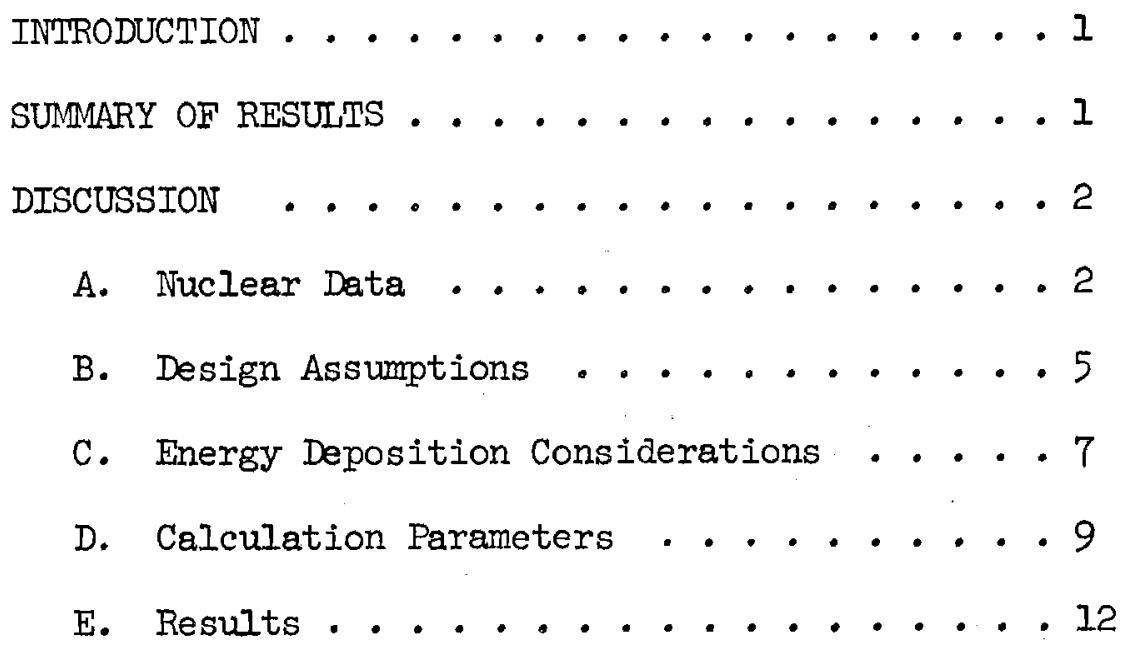


BNWL-648

\section{DECAY HEAT DEPOSITION FROM IRRADIATED FTR FUEL BUNDLE}

W. I. Bunch

\section{INTTRODUCTION}

Heat generated by irradiated FIR driver fuel is an important consideration in the design of equipment and facilities for storing and handing this material. Energy is liberated after the fuel has been irradiated as a result of the decay of the radioactive fission products. In facilities where the irradiated fuel is handled or stored, adequate cooling must be provided to remove this energy in order to maintain the fuel within prescribed temperature limits. The photons released in many of the decay processes transport part of the energy some distance before it is dissipated in the form of heat. It is necessary to consider the energy deposition pattern in order to determine cooling requirements for specific fuel handling processes. The present study has been directed at a preliminary evaluation of the decay energy deposition pattern in the fuel bundle to provide a basis for determining these cooling requirements. Because the deposition pattern is geometry dependent, more detailed studies might be indicated as the design of the fuel pins, bundles, and structure becomes more firmly established.

\section{SUMMARY OF RESULTS}

The calculated decay heat assoeiated th ForR driver fuel is shown in Figure 1. The three curves indicate (a) the total decay energy, (b) the total internally absorbed energy under the assumption that all fission products will be retained within the fuel, and (c) the total internally absoribed energy under the assumption that the halogens and noble gases will diffuse from the fuel into a remote plenum. The decay heat values are based on fuel operated continuously 


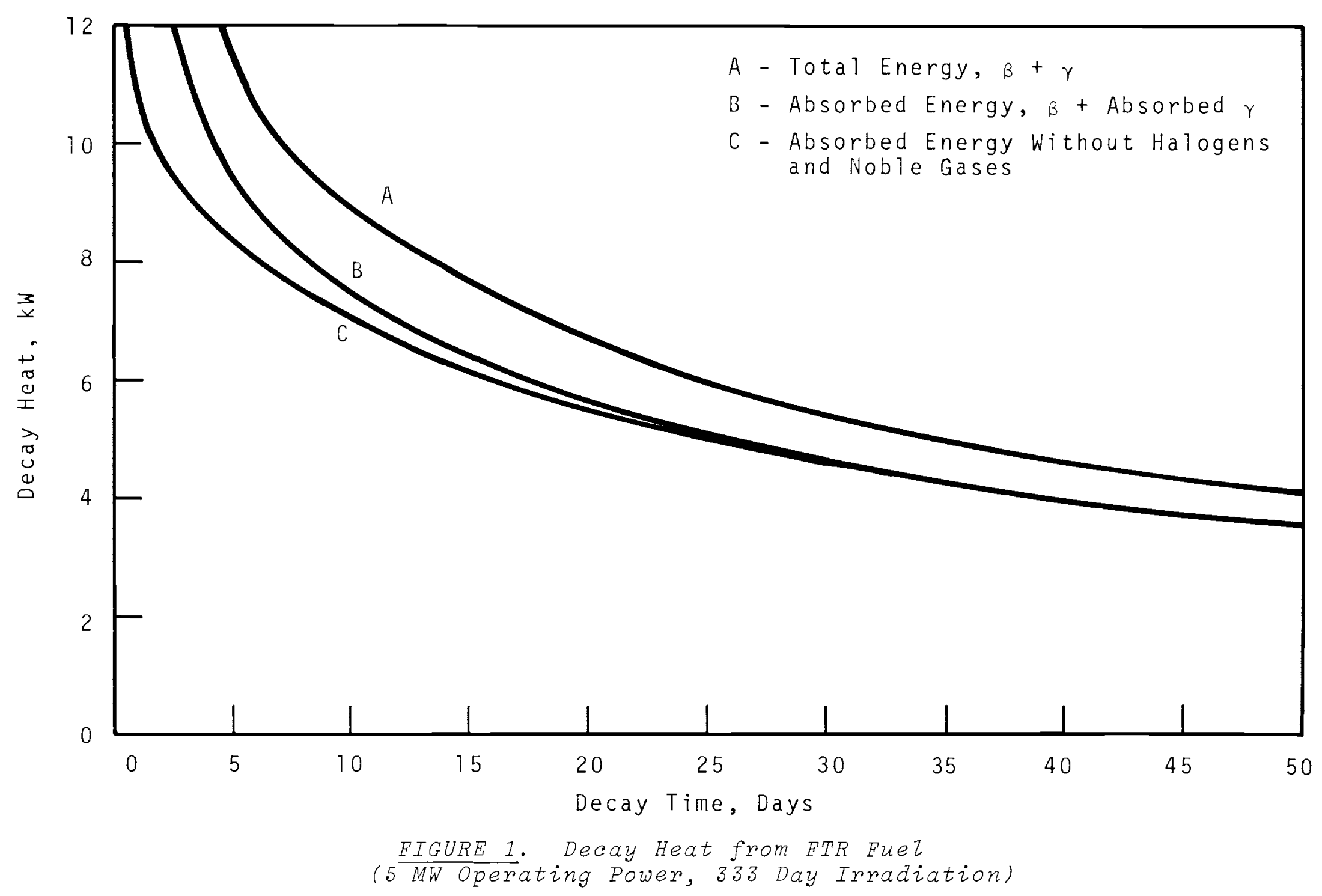


at a fission power level of $5 \mathrm{MW}$ to a goal exposure of approximately $45 \mathrm{MWD} / \mathrm{kg}$. Values for other fission power retes can be scaled directly; exposures in a wide range of interest for FIR would not be expected to affect the results significantly. Estimated axial distribution along the fuel region is shown in Figure 2 for the same three assumed conditions, based on a chopped cosine power distribution. All results are based on gamma escape from a homogenized cylindrical representation of the fuel bundle rather than from a discrete pin structure.

\section{DISCUSSION}

\section{A. Nuclear Data}

An analysical treatment of the production of decay heat in irradiated fuel is dependent on, and can be no better than, the nuclear data employed in the calculations. For this reason, a great deal of attention has been given to developing the nuclear data library for these calculations. Decay heat is related directly to the fission product inventory in the fuel. Since there are of the order of 450 different radioactive isotopes that can be formed in the fuel, a large quantity of nuclear data is required. For most isotopes, experimental data do not exist and it is necessary to use theoretical models normalized to available information. Because of the large number of isotopes involved, realistic theoretical models should provide valid bulk results because of the statistical averaging process that takes place. However, a relatively large uncertainty might be associated with any particular species due to anomalies not predicted by the model.

Key ruclear data for calculating the fission product inventory are the fission product yield factors. In a given fission event, a heavy and a light 


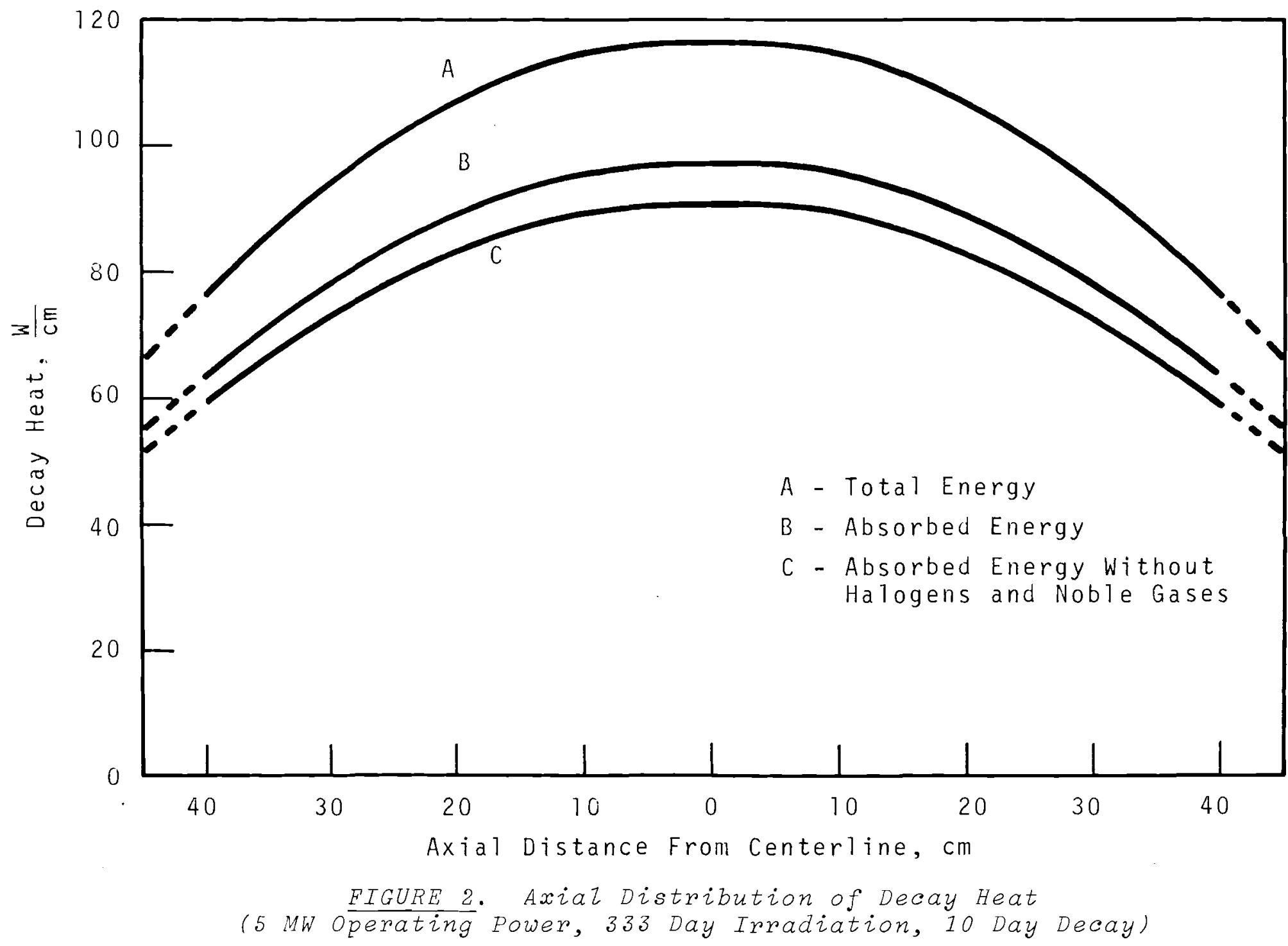


fission fragment are usually formed (ternary fission occurs in a negligible fraction of the events). (1) Fission product yields have been measured in some detail for the thermal fission of ${ }^{235} \mathrm{U}$, and to a lesser extent for the thermal fission of ${ }^{239} \mathrm{Pu}$. In addition, some measurements have been made for high energy (14 MeV) neutrons. It has not been possible to measure the direct yield of the short half life isotopes; therefore, cumulative yields of the stable or longer half life isotopes are the only ones obtained. Theoretical interpolation of the available information is required to provide direct yield values for all of the isotopes of interest. The present calculations are based on theoretical yield factors generated by Anderson. (2) Earlier studies of fission products in FrTR fuel (3) were based on a purely empirical fit of available data. (4) In both studies the total fission yield was normalized to two fission products per event; however, the direct yield factor for specific isotopes may differ significantly.

Fission products formed early in the irradiation can subsequently undergo a number of capture and/or decay events prior to discharge from the reactor. In order to include the effect of these events on the fission product inventory, cross sections and decay constants are required for each of the isotopes. Decay and capture are competing events whose relative importance can be influenced by the flux level, i.e., by the relative magnitude of the product of the flux and the capture cross section compared to the decay constant.

1. Earl K. Hyde, The Nuclear Properties of the Heavy Elements, Vol. III, Fission Phenomena, Chapter 4, Prentice-Hall, Inc. Englewood Cliffs, N. J., 1964.

2. C. A. Anderson, Jr. "Fission Product Yields from Fast Neutron Fission of Pu-239" LA-3383, Dec. 20, 1965.

3. W. I. Bunch, "Shielding Calculations for Irradiated FIR Fuel, "BNWL-342, December 1966.

4. W. L. Bunch, and D. R. Marr, "Fast Reactor Library for Use with RIBD," BNWL-CC-868, October 1966. 
Decay constants, which are inversely proportional to the half life, have been measured for nearly all of the fission products, (5) though there is a great deal of uncertainty associated with some of the short half life values. The latter uncertainty is of little practical importance in the present analysis, since the decay would take place prior to discharge of the fuel from the reactor. Also, the large decay constant associated with the short half life makes the decay process so dominant over the capture process that capture is effectively suppressed.

Energy dependent capture cross sections have been measured in detail for very few fission products. Many of the fission product isotopes have relatively large low energy or resonance capture cross sections that influence both the reactivity and the fission product inventory in thermal reactors. Such resonances are not expected to be important in the neutron energy spectrum of a fast reactor system. Fast reactor capture cross sections have been generated by Schenter $(6)$ for the FrR spectrum based on a compilation of existing data. Although these cross sections should be realistic, a significant uncertainty must be associated with any given isotope. Capture events are most important in stable isotopes or those wi.th long half lives, since only in those cases can capture compete favorably with the decay process.

Other nuclear data required for each isotope are the mode of decay and the energy associated with the decay process. For gross deca hegt

\footnotetext{
5. David T. Goldman, "Chart of the Nuclides," G. E. Co., Schenectady, N. Y., 1965.

6. R. E. Schenter, to be published, Battelle Northwest, Richland, Waeh.
} 
it is sufficient to know the total energy associated with the process. For evaluating the energy deposition pattern it is necessary to know the energy split between beta particles and photons, plus the photon spectral distribution. As discussed later, gamma deposition patterns are intimately related to the spectral distribution. A great deal of data of this type has been obtained and reported $(7)$; however, in many cases the reported values are inconsistent and/or imcomplete so that a selection must be made.

In addition to the nuclear data discussed above for each of the fission product isotopes, it is necessary to know the total energy associated with a fission event. The production rate of fission products is directly propontional to the fission rate, hence to the heat production rate of the fuel. The heat of fission is related to the reactor system. In uranium-fueled, graphitemoderated thermal reactors, the heat of fission is calculated to be about 200 $205 \mathrm{MeV}$ per fission event. In the plutonium fueled fast test reactor, the heat of fission is calculated to be $215.5 \mathrm{MeV}$. (8) The latter value has been used in the present study, whereas an arbitrary value of $200 \mathrm{MeV}$ was used in the earlier work. (3) The larger value for the heat of fission means proportionately fewer fission products will be generated in a plutonium-fueled reactor than in a uranium-fueled reactor at the same operating power.

B. Design Assumptions

The inventory of fission product present in the fuel will depend or the operating history. Two operating parameters are important: the spedific power level and the operating time. As indicated previously, the production rate

7. "Energy Levels of Nuclei: $A=5$ to $A=257$," Landolt-Bornstein, Numerical Data and Functional Relationships in Science and Technology, Ner Series, Vol. I, edited by K. H. Hellewege, Springer-Verlag, Berlin 1961.

8. W. L. Bunch, "Energy Deposition Distirubtion in the FTR," BNWL-563, Sept. 1967. 
of fission products is directly proportional to the power level. The irradiation time is required to establish specific relationships reached in the various decay and/or capture processes.

It has been assumed that a typical driver fuel element in the FrTR will generate about $5 \mathrm{MW}$. This value is based on a reactor power level of $400 \mathrm{M}$ with about 80 effective driver units. The exact number of driver channels has not been firmly established, but is conceptually considered to be about 76 . In addition, fuel contained in the open and closed loop test positions will generate some fraction of the total power. The results presented can be scaled directly to estimate decay heat rates in assemblies operated at higher or lower powers.

It has been assumed that the goal exposure of the driver fuel will be about $45 \mathrm{MWD} / \mathrm{kg}$ and that this exposure will be achieved in one continuous operating period. The latter assumption is conservative but realistic. For isotopes with half lives that are short compared to the operating period, an equilibrium or saturation value is achieved. The inventory of isotopes with very long half lives tends to integrate over the entire exposure. Those isotopes with half lives comparable to the length of the exposure are most strongly influenced by the actual exposure time and by the existence of operating cycles. For high operating efficiency, the cyclic nature of the operation is a second order effect that does not strongly influence the fission product inventory. Thus, the results need not be scaled for other goal exposures, but are realistic for a relatively wide range of exposures about the assumed go8l. 
The core and fuel loadings have not been firmly established at this time. Core analyses indicate that a typical loading will require about $3000 \mathrm{~kg}$ of fuel for the split conicel concept. It was assumed in the present study that each bundle would contain $37 \mathrm{~kg}$ of fuel; therefore, an Irradiation time of 333 days was used in the calculation.

The exact fuel geometry is not well defined at this time. The present concept consists of a cluster of about 217 pins on a triangular pitch to form a hexagonal array. Each pin would be about 0.25 inches outside diameter and consist of sixteen mil thick stainless steel cladding encasing mixed uranium-plutonium oxide fuel. Wire wrap would be used to separate the pins to provide coolant space, and the hexagonal array of pins would be contained in a flow duct about 4.25 inches across flats. The final design is expected to evolve from this concept as a result of the fuel development program in progress.

\section{Energy Deposition Considerations}

The deposition pattern of the decay energy associated with the fission products is dependent on the system geometry. Energy associated with the beta particles is deposited in the immediate vicinity of the decaying isotope, whereas the photon energy can be deposited at some distance. Thus, to define the deposition patterns, it is necessary to know the energy split between beta particles and photons, and also the spectral distribution of the photons. Existing compilations of this type of data are both incomplete and inconsistent; therefore, energy deposition patterns are subject to greater uncertainty than is the total decay energy rate.

Beta particles lose energy quite readily when passing through matter as a result of ionizing interactions with orbital electrons. Except for hydrogen, 
equal masses of material contain approximately the same number of orbital electrons. Therefore, the range of beta particles is essentially the same (in units of $\mathrm{g} / \mathrm{cm}^{2}$ ) in all materials and is dependent on the initial energy. To a first approximation, the range in $\mathrm{g} / \mathrm{cm}^{2}$ is half the magnitude of the initial beta particle energy in $\mathrm{MeV}$. Thus, the range of a $1 \mathrm{MeV}$ beta particle is about $0.5 \mathrm{~g} / \mathrm{cm}^{2}$. In oxide fuel with a density of $10 \mathrm{~g} / \mathrm{cm}^{3}$, such a beta particle would travel about $0.05 \mathrm{~cm}$. The stainless steel cladding around fuel pins is expected to contain about $0.3 \mathrm{~g} / \mathrm{cm}^{2}$; thus, it is realistic to assume that all of the beta energy will be deposited within the fuel and clad.

Deposition of the energy associated with photons resulting from the decay process cannot be treated so easily. Of the dozen interaction processes whereby photons lose energy in traversing matter, only three (photo-electric absorption, Compton scattering, and pair production) are expected to play important roles in the attenuation of the decay photons. These processes are lumped together to form an energy-dependent interaction cross section for materials of interest. In narrow beam or "good geometry" cases, this cross section can be used to describe the exponential attenuation of a morororgetic photon beam. The same cross section is used for bulk shields by the application. of appropriate energy dependent buildup factors. This procedure is progmammed in ISOSHID ${ }^{(9)}$ using point kernel techniques for speeific geometries and Taylor buildup factors.

The microscopic detaic of the energy deposition associated with the photons is obviously dependent on the geometry of both the iratioual fuel. 
pins in a bundle and the arrangement of the pins within the bundle. As indicated, these details are not firmly established for the FIR, but are the subject of a continuing program to optimize the many parameters. Ireating an exact pin geometry in detail is a complex and time consuming task; therefore, it was considered adequate for this preliminary calculation to approximate the bundle by a homogeneous cylinder containing an appropriate quantity of fuel, cladding, and space. An estimate of the importance of the bundle compaction was made by varying the radius and density of the homogeneous mixture. It is deemed unlikely that details of the fuel pin arrangement will significantly influence the fraction of the photon energy deposited within the assembly.

\section{Calculation Parameters}

The fission product inventory was calculated using the computer program RIBD. (10) Input parameters required for the calculation include the neutron flux, the strength of the shutdown event, the neutron lifetime, and the kind of fuel. A value of $5 \times 10^{15} \mathrm{n} / \mathrm{cm}^{2} \mathrm{sec}$ was assumed for the neutron flux. Flux is required in order to include the effect of neutron capture in the fission products, and is always used in conjunction with the capture cross section ard decay constant for a particular isotope. Parametric calculations indicate that. the total decay heat is relatively insensitive to the flux value in the range of interest for FIIR studies. However, the concentration of individual isotopes might be affected if the flux-cross section product is large compared to the decay constant.

It was assumed in the calculations that a typical FIR shutdown would be achieved by insertion of $30 \mathrm{mk}$ of negative reactivity. The actual value for

10. R. O. Gumprecht, Unpublished Data, Douglas United Wuclear, Richand, Washington, Feb. 1966. 
any given shutdown will depend on the previous operating history and the particular situation at the time. The strength of the shutdown mechanism only influences the decay heat rates for the first few minutes (while delayed neutrons sustain the fission process) and does not affect the present study. A neutron lifetime of 1 microsecond was used in the calculations, since this is the smallest value the program will accept. Core analyses indicate an actual value of about 0.3 microseconds. The neutron lifetime influences decay heat only for the first few minutes following shutdown when a significant number of fission events are still occurring due to the delayed neutrons.

Fission product yield factors are included in the RIBD Iibrary for both ${ }^{235} \mathrm{U}$ and ${ }^{239} \mathrm{Pu}$. It is possible to generate the fission products for a reactor fueled with either of these isotopes or with any combination of them. It was assumed in the present study that essentially all fission events would be due to ${ }^{239} \mathrm{Pu}$. It is also assumed that fission of ${ }^{238} \mathrm{U}$ wiII produce the same fission product distribution as fission of ${ }^{239} \mathrm{Pu}$.

It was assumed in most cases that the fueled portions of the pins would be $90 \mathrm{~cm}$ long. On the basis of core calculations, an effective extrapolation length of $28 \mathrm{~cm}$ was used with a cosine function to approximate the axial powrer distribution. A flat radial distribution across each bundle was assumed. Input information is summarized in Table I for the ISOSHID calculations t. estimate the fraction of gamma energy deposited in the fuel. These values are based on a 217 pin assembly with $16 \mathrm{mil}$ steal cladding and a mixed oxide fuel density of $10.0 \mathrm{~g} / \mathrm{cm}^{3}$.

Three ISOSHID calculations were made for each of the geometries assumed. In the first case it was assumed that all of the fission products were present. 
Table I

INPUT PARAMEILES FOR ISOSHLD CALCULATIONS

\section{Common to all Calculations}

Operating Power of Fuel

5 MW

Exposure Time

333 days

Neutron Flux

$5 \times 10^{15} \mathrm{n} / \mathrm{cm}^{2} \mathrm{sec}$

Heat of Fission

$215.5 \mathrm{MeV}$

Fuelec Ieneth

$90 \mathrm{~cm}$

Frel

239Pu

Bundle radius, cm

$\frac{\text { Configuration }}{\frac{1}{5.5}} \frac{\frac{2}{6.0}}{2}$

Bundle density, $\mathrm{g} / \mathrm{cm}^{3}$

6.86

5.73

Shroud thickness, cm

0.5

0.5

Shroud density, $6 / \mathrm{cm}^{3}$

7.8

7.8 
In the other cases it was assumed that only the halogens or the noble gases were present. By an appropriate combination of the results, the deposition fraction of interest was obtained. The two different assumed fuel compactions yielded a difference in the gamma fraction absorbed of the order of $10 \%$, which gives an indication of the relative importance of the fuel design. The more conservative values were assumed in the final analyses. The more optimistic values would reduce the plotted internally absorbed energy values by about $5 \%$.

E. Results

Results of the calculations are summarized in Tables II and III and in Figures 1 and 2. Table II summaxizes the results of the RIBD calculations to estimate beta and gamma decay heat as a function of time after irradiation. The halogens and noble gases are listed separately from the other fission products to indicate the relative contribution of these elements. Table III summarizes the ISOSHLD calculations to estimate the fraction of the gamma energy absorbed in the fuel array. Two different fuel arrays were considered, one in which the pins would be spaced to approximate a cylinder $5.5 \mathrm{~cm}$ in radius and the other $6.0 \mathrm{~cm}$. In both cases it was assumed the bundle would be encased by a $0.5 \mathrm{~cm}$ thick steel shroud tube to direct the flow of coolant. As indicated by the results, garma energy absorbed by the fuel will be influenced slightly by the compaction of the pin array.

By an appropriate combination of the information presented in Table II and III, the curves in Figure $I$ were generated. Curve $A$ is the total energy associated with the beta-gamma decay of the fission products. Curve $\mathrm{E}$ is the calculated self absorbed energy under the assumption that ali of the fission products will remain within the fuel. Cumve $\mathrm{C}$ is the absorbed energy within the 
Table II

FISSION PRODUCT DECAY ENERGY, KW

(5MW operating powex, 333 day exposure)

$\begin{array}{lllllllllll}0 & 1 / 3 & 5 & 10 & 50 & 50 & 100\end{array}$

Beta Power

Halogens

Noble gases

other Fission Products

$\begin{array}{rrrrrrrrrr}10.3 & 1.29 & .85 & .279 & .122 & .034 & .012 & .002 & .000 & .000 \\ 8.5 & 0.57 & .31 & .083 & .044 & .012 & .003 & .000 & .000 & .000 \\ 102.2 & 9.25 & 6.19 & 4.036 & 3.420 & 2.797 & 2.424 & 1.979 & 1.720 & 1.472 \\ 121.0 & 11.11 & 7.35 & 4.398 & 3.586 & 2.843 & 2.439 & 1.981 & 1.720 & 1.472\end{array}$

Total $\beta$

Gamma Power

Halogens
Noble Gases
Other Fission Products
Total $\gamma$

$\begin{array}{rrrrrrrrrr}15.63 & 4.08 & 2.67 & 1.011 & 0.410 & .091 & .029 & .005 & .000 & .000 \\ 6.10 & 0.65 & 0.29 & 0.072 & .037 & .010 & .003 & .000 & .000 & .000 \\ 48.38 & 10.51 & 7.38 & 5.978 & 4.955 & 3.708 & 2.939 & 2.062 & 1.585 & 1.151 \\ 70.11 & 15.24 & 11.34 & 7.061 & 5.402 & 3.809 & 2.971 & 2.067 & 1.585 & 1.151\end{array}$


Table III

FRACTION OF GAMMA RADIATION ABSORBED IN THE FUHL

\begin{tabular}{ll} 
DECAY TIME - DAYS \\
\hline $0 \quad 10 \quad 20 \quad 30 \quad 50$
\end{tabular}

All Fission Products

$5.5 \mathrm{~cm}$ radius

$\begin{array}{lllll}.659 & .729 & .737 & .742 & .745\end{array}$

$6.0 \mathrm{~cm}$ radius

$\begin{array}{lllll}.634 & .708 & .717 & .721 & .724\end{array}$

Halogens Only

$5.5 \mathrm{~cm}$ radius

$\begin{array}{lllll}.608 & .672 & .782 & .816 & .886\end{array}$

$6.0 \mathrm{~cm}$ radius

$\begin{array}{lllll}.581 & .651 & .766 & .800 & .875\end{array}$

Noble Gases

$5.5 \mathrm{~cm}$ radius

$6.0 \mathrm{~cm}$ radius

$\begin{array}{lllll}.743 & .969 & .969 & .969 & .967 \\ .724 & .971 & .971 & .971 & .969\end{array}$ 
fuel under the assumption the noble gases and halogens will evolve from the fuel into a plenum region.

Figure 2 presents estimates of the axial energy deposition distributiox along the fuel bundle ten days following shutdown. The three curves are for the same three cases as above; i.e., total energy, absorbed energy, and absorbed energy without halogens and noble gases. These distributions are based directly on a chopped cosine power distribution. The desposition rate would be expected to drop slightly at each end of the bundle because of gamma. leakage; however, the effect was considered to be nagligible from the stardp int of heat removal requirements and was not pursued in detain.

Calculations were also made for $80 \mathrm{~cm}$ long fueled regions. These yielded essentially the same fractional gamma absorption within the fuel. Thus, axial distributions in other fuel lengths in the range $80-90 \mathrm{~cm} \mathrm{can}$ be approximsted by:

$$
P(x)=\frac{P \cos \left(\frac{\pi x}{I+56}\right)}{\left(\frac{2 I+i I 2}{\pi}\right) \sin \left(\frac{\pi I}{2 I+I I 2}\right)}
$$

where $P$ is the total decay heat of interest assceiated with the fue $I$ an $I$ is the fueled length in $\mathrm{cm}$. 
DISTRIBUTION

U. S. Atomic Energy Commission

Division of Reactor Dev \& Tech

M Shaw, Director, RDT

Asst Dir for Nuclear Safety

Analysis \& Evaluation Br, RDT:NS

Environmental \& Sanitary Engrg Br, RDT : NS

Research \& Development Br, RDT:NS

Asst Dir for Plan Engrg, RDT

Applications E Facilities Br, RDT:PE

Components $\mathrm{Br}, \mathrm{RDT}: \mathrm{PE}$

Instrumentation $\&$ Control Br, RDT:PE

Systems Engineering $\mathrm{Br}, \mathrm{RDT}: \mathrm{PE}$

Asst Dir for Program Analysis, RDT

Asst Dir for Project Mgmt, RDT

Liquid Metals Projects Br, RDT:PM

FFTF Project Manager, RDT:PM (3)

Asst Dir for Reactor Engrg

Control Mechanisms Br, RDT:RE

Core Design Br, RDT:RE

Fuel Fabrication $\mathrm{Br}, \mathrm{RDT}: \mathrm{RE}$

Fuel Handling $\mathrm{Br}$, RDT: RE

Reactor Vessels Br, RDT:RE

Asst Dir for Reactor Tech

Chemistry \& Chemical Separations

$\mathrm{Br}, \mathrm{RDT}: \mathrm{RT}$ (2)

Fuels \& Materials Br, RDT:RT

Reactor Physics Br, RDT:RT

Special Technology Br, RDT:RT

1 AEC Chicago Patent Group

GH Lee, Chief

Patents

RK Sharp

1 AEC Idaho Operations Office

Nuclear Technology Division

CW Bills, Director

4 AEC Richland Operations Office

FFTF Project office (2)

Engineering \& Construction Div (1)

JH Krema 


\section{DISTRIBUTION, Continued}

1 AEC San Francisco Operations Office Director, Reactor Division

4 AEC Site Representatives - PNL PG Holsted (2)

LR Lucas

$\mathrm{AD}$ Toth

4 AEC Site Representatives Argonne National Laboratory Atomics International Atomic Power Development Assoc. General Electric Co.

2 Argonne National Laboratory RA Jaross LMFBR Program Office

2 Atomics International LE GIasgow Liquid Metal Engrg Center RW Dickinson

1 Atomic Power Development Assoc. BVD Farris

2 Babcock \& Wilcox Co. Atomic Energy Division SH Esleeck

Boiler Division TP Farrel1

1 Combustion Engineering 1000 MWe Follow-On Study WP Staker, Project Manager

2 General Dynamics Corp. General Atomic Div. D Coburn

4 General Electric Co. Advanced Products Operation Kar1 Cohen (3)

1 Idaho Nuclear Corporation DR deBoisblanc

1 PNL Representative NA Hil1 (ZPR-III) 
1 Stanford University

Nuclear Division

Division of Mechanical Engrg

$\mathrm{R}$ Sher

5 Westinghouse Electric Corp.

Atomic Power Division

Advanced Reactor Systems

JCR Kelly

91 Battelle Northwest
GE Akre
WG Albert
So Arneson
ER Astley
JM Batch
TA Bauman
RA Bennett
JR Boldt
CL Boyd
DC Boyd
CL Brown
WL Bunch (10)
CP Cabell
AC Callen
JR Carrell
WE Cawley
WL Chase
TT Claudson
PD Cohn
DL Condotta
RR Cone
JH Cox
JM Davidson
BR Hayward
JW Helm
RJ Hennig
GM Hesson
PL Hofmann
BM Johnson
HG Johnson
$\mathrm{JH}$ Kinginger
DD Lanning
HD Lenkersdorfer
$\mathrm{CW}$ Lindenmeier
HE Little
WW Little
WB McDonald
$\mathrm{MH}$ Meuser
RA Moen
CA Munro
DM Nero
MG Patrick
JA Perry
RE Peterson
WE Roake
JD Schaffer
VA DeLiso
FH Shadel
DW Shannon
DE Simpson
(2)
GE Driver
CRF Smith
RV Dulin
JF Erben
RJ Squires
LM Finch
RC Free
EE Garrett
DD Stepnewski
SM Gill
VW Gustafson
RA Harvey
GH Strong
CD Swanson
JC Tobin
KG Toyoda
MA Voge 1

(2) DM Walley

JH Westsik

LA Whinery

RD Widrig

TW Withers

NG Wittenbrock

MR Wood

FW Woodfield

FFTF File (2) 